\title{
A METALITERATURA, O HIPERTEXTO E AS INTERARTES EM BONSAI, DE ALEJANDRO ZAMBRA
}

LA METALITERATURA, EL HIPERTEXTO Y LAS ENTRE ARTES EN BONSÁI, DE ALEJANDRO ZAMBRA

Alexandre Miguel da Silva

RESUMO: A partir das metáforas produzidas pelos elementos da natureza no romance Bonsai (2014), de Alejandro Zambra, o texto discute a ideia de jardim e estufa a partir dos conceitos propostos por Andreas Huyssen e Anne Cauquelin. Deste ponto, o ensaio analisa e discute os símbolos da natureza no romance pela perspectiva da metaliteratura e o hipertexto a partir do marco teórico de Gérad Genette. As relações entre interartes o editorial são embasados por Claus Clünver, Luise Fialho e Ana Grunsznski.

PALAVRAS-CHAVE: Literatura Contemporânea; Imagens da Natureza; Bonsai.
* alexandremiguel.dasilva2@gmail.com

Mestrando em Estudos Literários pela Universidade Federal de Minas Gerais (UFMG).

RESUMEN: A partir de las metáforas producidas por los elementos de la naturaleza en el romance Bonsái (2014), de Alejandro Zambra, que el texto pone en discusión el jardín y la estufa
desde los conceptos propuestos por Andreas Huyssen y Anne desde los conceptos propuestos por Andreas Huyssen y Anne Cauquelin. Desde ese punto de partida, el ensayo analiza los símbolos de la naturaleza del romance y discute la metaliteratura el entre artes y el editorial están pensadas desde los teóricos Claus Clünver, Luise Fialho y Ana Grunsznsi.

PALABRAS-CLAVES: Literatura Contemporánea; Imágenes de la naturaleza, Bonsái. 
1. CAUQUELIN, 2007, p. 62.

2. CAUQUELIN, 2007, p. 63.
Como a arte pensa a natureza? Quando falamos em pensar a natureza diante da arte, são as pinturas, fotografias e as imagens os primeiros elementos que nos vêm à mente. Portanto, para responder essa pergunta, podemos buscar exemplos nas mais diversas pinturas e fotografias de paisagens que existiram e existirem, delineando a trajetória do mundo até a contemporaneidade. As pinturas e fotografias, em geral, são trazidas para um a mbiente urbano, o que, além de mostrar a natureza em sua forma nua e crua, escancara para a sociedade moderna o seu distanciamento do natural, daquilo que o "campo oferece", isto é, "[...] a calma, a abundância, o frescor e bem supremo, o ócio para meditar, longe dos falsos valores"

Não muito distante das pinturas e fotografias, a literatura também pensa, por diferentes vieses e perspectivas, a natureza como urbano e rural, das espécies irracionais ao homem racional. Quer dizer, a literatura tem explorado a natureza e suas diversas estéticas narrativas diferentes, cuja forma da natureza é representada em decorrência da época das produções de suas obras. A natureza na literatura é descrita desde a catástrofe, como em Vozes de Tchernóbil: crônica do futuro (1997) de Svetlana Aleksiévitch, à sua grandiosidade, como em Grande Sertão Veredas de Guimarães Rosa (1956), ou até mesmo sua fúria e proporção desértica ao utópico ${ }^{2}$ como em Utopia (1516) de Thomas More. No espaço da literatura latino-americana, a natureza já esteve presente em romances do brasileiro Aluísio Azevedo, como em O mulato (1881), em narrativas como Macunaíma (1928) de Mário de Andrade, Vidas secas (1938) de Graciliano Ramos, Um, dois e já (2014) da uruguaia Inés Bortagaray, Limoeiro real (1974) do argentino Juan José Saer.

No âmbito da escrita contemporânea, obras resgatam a representatividade da natureza, conciliando-a com o caos da modernidade e as relações modernas. A exemplo, está Bonsai (2014), o primeiro romance do escritor Alejandro Zambra ${ }^{3}$. Cruel e triste por si só, Bonsai (2014) contempla o ser humano na sua vida ultramoderna ${ }^{4}$, descrevendo relações que se desintegram, além do cotidiano, o suicídio e a relação do homem com um bonsai, que é uma árvore em miniatura ${ }^{5}$. O romance, desfabular e denso, como afirma Emilio Fraia no texto de orelha do livro, tem uma a história que enuncia, em suas primeiras linhas, a "consciência do fim"6. O desenlace esta mpado em seu parágrafo de abertura, diz: “[...] no final ela morre e ele fica sozinho, ainda que na verdade ele já tivesse ficado sozinho muitos anos antes da morte dela, de Emília."7. Bonsai (2014) é uma narrativa compacta que conjuga a metaliteratura, o hipertexto, as interartes e, na edição brasileira, o trabalho editorial.

Narrado em terceira pessoa, Bonsai (2014) apresenta informações inconclusas sobre suas personagens, em que "[...] digamos que ela se chama ou se chamava Emília e que ele se
3. Alejandro Zambra Infantas nasceu em Santiago do Chile, em 1975, e é autor de dois poemarios intitulados Bahía inútil (1988) e Mudanza (2003); da coletânea de ensaios No leer (2018); de um livro de contos, Mis documentos (2014); (2014), A vida privada das árvores 2013), Formas de voltar para casa (2014) publicados no Brasil pela extinta Cosac Naify.

4. VOLPATO, Cadão. Zambra, um escritor com espírito de botânico. Valor Econômico, 4 abr. 2013.

valor.com.br/cultura/3072360/

zambra-um-escritor-com-espiritode-botanico>. Acesso em: 17 jun. 2019.

5. As obras de Alejandro Zambra também dão destaque a um caráter urbano, em que a cidade, as relações do homem com as novas mudanças políticas e o estilo de vida do jovem nas décadas de 90 e dos anos 2000 são temas. $O$ anonimato e a fragmentação das personagens também são características de sua escrita, no qual, seus narradores se destacam por sua autonomia

6. FRAIA, 2014. [texto de orelha do livro]

7. ZAMBRA, 2014, p. 10 


\section{ZAMBRA, 2014, p. 10.}

9 ZAMBRA, 2014, p. 44

10. Todas as vezes que o conto Tantalia for referenciado no texto, em referência a edição publicada na Antologia de Literatura Fantástica (1940) do Jorge Luis Borges, Adolfo Bioy Casares, Josely Vianna Baptista.

11. Uma das correntes literárias presentes na narrativa chilena recente é o "realismo como Álejandro Zue "Zambra, Diego Zúñiga (Camanchaca), Alejandra Costamagna (Animales domésticos), Nona Fernández (Fuenzalida), tentam dar conta do empo presente, por meio de uma Itteratura "que desagua em situações concretas e contemporâneas" (SCHIFINO apud WILLEM, 2016 p. 313). Em seus escritos, esses autores observam de maneira (WILLEM, 2016, p. 313) a enorm complexidade social, política, cultural e racial que vivenciam.

12. ZAMBRA, Bonsai, 2014, p. 80 chama, se chamava e segue se chamando Júlio"', nivelando os protagonistas como as personagens secundárias:

[...] marido de Anita se chamava Andrés, o Leonardo. Vamos dizer que o seu nome era Andrés e não Leonardo. Vamos dizer que Anita estava acordada e Andrés quase dormindo e as crianças estavam dormindo na noite em que imprevistamente Emília chegou para visitá-los. ${ }^{9}$

O romance possui cinco unidades mínimas/capítulos "Vulto", "Tantalia"10, "Empréstimos", "Sobras" e "Dois desenhos" - limitando-se a colocar em xeque, em poucas páginas, a relação de Emília e Júlio, construída e finalizada a partir da literatura. Não sendo apenas sobre o esfa rela mento das relações humanas, a narrativa é também sobre a continuidade e a nostalgia do homem sobre elas. Conforme se desenvolve, é possível aderir à ideia do minimalismo ${ }^{11}$ dos detalhes em sua estrutura, semelhantes à do cuidado da árvore em miniatura, em que a escolha do recipiente "[...] por si só, [é] quase uma forma de arte." ${ }^{12}$ As imagens distribuídas no romance não apresentam informações profundas, para além do essencial, isto é, estão distribuídas em formato de um bonsai, sem ramificações ou expansões detalhistas sobre as vidas de seus personagens.

Retomando a Emílio Fraia, Bonsai (2014) é uma obra moldada à miniatura, que questiona a instabilidade do gênero romance, cuja estrutura é escancarada para o mundo exterior ${ }^{13}$. Um narrador autônomo e desleixado joga com a metaliteratura e o hipertexto, movendo referências para dentro e fora de sua história. Junto ao exercício narrativo, a edição brasileira do romance traz à luz os efeitos da interação entre a arte construída na edição com o conteúdo dentro do livro O romance é uma colagem de referências internas e externas dos quais, sobre esses aspectos, destacamos: o hipertexto e a metaliteratura, a contribuição editorial e a relação entre interarte de cultivar um bonsai, escrever um romance e a produção do livro físico.

\section{Semear a literatura}

A relação amorosa das personagens Júlio e Emília não é alicerçada com base apenas em suas extravagâncias sexuais, "nem emocionais (que eram muitas), mas também, digamos, literárias." ${ }^{14} \mathrm{O}$ hábito das personagens de lerem em voz alta, "antes de trepar"15, começou numa noite em que Júlio "[... leu, no meio de uma brincadeira, uma poema de Rubén Darío que Emília dramatizou e banalizou até transformá-lo num verdadeiro poema sexual, um poema de sexo explícito, com gritos, com orgasmos."16 Bonsai (2011) traz, explicitamente, nomes de autores como Rubén Darío, Marcel Schwob, Yukio Mishima, Tolstoi, Flaubert, Marcel Proust e Macedonio Fernández. Destes autores, Marcel Proust e Macedonio
13. VOLPATO, Cadão. Zambra, um escritor com espírito de botânico. Valor Econômico, 4 abr. 2013 Disponivel emi. htes://whw.valor. um-escritor-com-espirito-deGotanico. Acesso em: 17 jun. 2019.

14. ZAMBRA, 2014, p.28 15. ZAMBRA, 2014, p.28

16. ZAMBRA, 2014, p.28 
17. GENETTE, 2010, p. 16

18. GENETTE, 2010, p.16, grifo nosso.

19. É importante ressaltar que Bonsai poderia constituir-se segundo romance de Alejandro Zambra, A vida privada das árvores (2013), em que a personagem se declara autor de um livro cuja personagem se contenta em cuidar de sua arvore em miniatura. A dissertação de Diego Perez (2016) desenvolve
Fernández se destacam porque suas narrativas proporcionam o efeito metaliterário e de hipertexto e hipotexto.

Gérard Genette (2010) apresenta em Palimpsestos: a literatura de segunda mão os conceitos de hipertexto e hipotexto. Para o autor, a hipertextualidade é "[...] toda relação que une um texto B (que chamarei hipertexto) a um texto anterior A (que, naturalmente, chamarei hipotexto)" ${ }^{\prime 17}$. Essa relação pode ser dar por uma ordem

[...] em que B não fale nada de A, no entanto não poderia existir daquela forma sem $\mathrm{A}$, do qual ele resulta, ao fim de uma operação que qualificarei, provisoriamente ainda, de transformação, e que, portanto, ele evoca mais ou menos manifestadamente, sem necessariamente falar dele ou citá-lo. ${ }^{18}$

No caso em a nálise, a transformação evocada por Zambra é derivada por duas ordens. ${ }^{19}$ Bonsai (2014) (B) faz uma referência direta ao conto Tantalia (A1), de Macedônio Fernandez e, mais adiante, evoca Em busca do tempo perdido (1913) (A2), de Proust. A soma da união entre os hipotextos A1 +A2 é o que concebe (B) o hipertexto, porque o sentindo de Bonsai (2014) não poderia existir sem as obras anteriores.

A soma desses elementos literários, produz, dentro do corpo do romance, a metaliteratura, da qual entendemos por metaliterário “[...] a presença da literatura como tema central das narrativas" ${ }^{20}$, em que "[...] o fato da literatura falar sobre si mesma que dá a essa estratégia um caráter autorreflexivo." ${ }^{21} \mathrm{O}$ narrador zambria no enuncia a união entre $\mathrm{B}+\mathrm{A} 2$ com a citação do romance de Proust. O rompimento do relacionamento das personagens ocorre quando elas abandonam a leitura, na seguinte passagem de Proust:

Não é porque se sabe de uma coisa que se pode impedi-la; mas temos pelo menos as coisas que averiguamos, se não entre as mãos, ao menos no pensamento, e ali estão à nossa disposição, o que nos inspira a ilusão de exercer sobre elas uma espécie de domínio. ${ }^{22}$

A relação entre a citação, no livro de Zambra, de Em busca do tempo perdido e Bonsai se dá, por exemplo, com o início do romance, em que o narrador anuncia: "[...] no final ela morre e ele fica sozinho, ainda que na verdade ele já tivesse ficado sozinho muitos anos antes da morte dela, de Emília." ${ }^{23}$ Saber da morte de Emília, que será fatual, e que não se pode impedi-la, torna coerente a ligação com Proust, pois, não se contentando, o narrador decide exercer o domínio sobre a história na qual ele diz que "[...] o resto é literatura:"24 utilizando o símbolo de dois pontos (:) para ilusionar a sua possível criação literária após a afirmativa de Emília morre e Júlio fica sozinho final.
20.HUTCHEON apud SOUZA, 2012, p. 171.

21.HUTCHEON apud SOUZA 2012, p. 171.

22. 36

23 ZAMBRA, 2014, p. 10.

24. ZAMBRA, 2014, p. 10 
25. É importante notar que além de desencadea amorosa de Júlio e Emília ele exerce também função de uma crítica à literatura latino-americana. Desde a leitura Tantalia, de autor latinoamericano, os personagens decidem recorrer aos autores clássicos como Faulkner, Kafka, Tchekhov Proust, “[...] talvez para amenizar a decepçao, ou simplesmente mudar exclusivamente a clássicos." Cf: ZAMBRA, 2014, p. 32. Para manter a relação amorosa alicerçada como se, para uma garantia de sua relação amorosa, deve-se recorrer aos pilares. Para reforçar tal crítica, recordo ao leitor da passagem em que Júlio, por falta de dinheiro, decide vender alguns livros. Todos os livros vendidos por Júlio são de autores latino americanos. Dá qual, podemos associar a facilidade de 79- 80. É válido pensar também que o dinheiro dos livros foi utilizado para comprar materiais para fazer o seu próprio bonsai, no qual podemos pensar na renovação e estruturação da literatura latino-americana. Cf.: SANTOS, Daniel. A crise da ficção na historia literaria latino-americana: ○ caso Alejandro Zambra. $\mathbf{X}$ Seminario Internacional de Historia Anais. Disponível em: www Alegre. pucrs.br/edipucrs/Ebooks/Web/ xsihl/media/comunicacao-17. pdf. Acesso em: 15 jun. 2019

26. ZAMBRA,2014, p. 29.

27. ZAMBRA, 2014, p. 70
O conto Tantalia ${ }^{25}$ (B1) do argentino Macedônio Fernández é o propulsor que faz desandar a relação a morosa entre Júlio e Emília. O conto, que em resumo, é

[...] a história de um casal que decide comprar uma plantinha para conservá-la como símbolo do amor que os une. Percebem tardiamente, que se a plantinha morrer, morrerá com ela o amor que os une. E como o amor que os une é imenso e por nenhum motivo estão dispostos a sacrificá-lo, decidem fazer a plantinha se perder entre uma multidão de plantas idênticas Depois ficam inconsoláveis, infelizes por saber que nunca mais poderão encontrá-la. ${ }^{26}$

Sendo a pulsão para o fim da relação das personagens, a presença do conto de Fernandez propõe uma assimilação de valores, em que a "plantinha" de Júlio e Emília seria o hábito extravagante de ler, antes do sexo, um trecho literário e que, quando deixarem de fazer isso, o amor dos dois poderiam se perder. Ademais, cria-se um paralelo entre o conto (A1) e a narrativa de Alejandro Zambra (B), pois, o amor das personagens esfacela-se quando elas se deparam com o conto, mas Júlio só vem construir a sua "arte”, os seus bonsais (livro e árvore), símbolo de um amor, anos depois, quando percebe que "[...] todas as suas garotas (Maria e Emília) vão embora para Madri. "27 Júlio faz o seu bonsai porque "[...] ele nunca se esqueceu dela [...]" e que "[...] desta vez ele não compra, ele mesmo o faz." ${ }^{28}$ A imagem produzida pelo conto de Macedônio Fernández é o que posteriormente causa rá a Júlio uma nostalgia referente à sua relação com Emília, pois é uma mescla entre o conto do escritor argentino e a ficção que Júlio escreve o que desperta a motivação para fazer seu próprio bonsai.

O outro modo como a natureza e reflexão metaliterário se revela em Bonsai (2014) é a partir da decisão e do cuidado de Júlio em fazer o seu próprio bonsai (árvore) e o seu próprio livro. A fim de exemplificação, um fragmento:

Pelas manhãs ele vai atrás, a contragosto, de um trabalho estável. Volta para casa no meio da tarde, mal come alguma coisa e já se debruça sobre os manuais: procura a maior sistematicidade, invadido que está por um vislumbre de plenitude. Lê até ser vencido pelo sono. Lê sobre as doenças mais comuns entre os bonsais, sobre a pulverização das folhas, sobre a poda, sobre o alambrado. Consegue, por último, sementes e ferramentas.

E faz. Faz um bonsai. ${ }^{29}$

Júlio, ao descobrir que bonsai é "[...] uma réplica artística de uma árvore em miniatura [...]”30 e que a "[...] seleção do vaso apropriado para uma árvore é, por si só, quase uma forma de arte [...]"31, trata de comparar, envergonhado, a árvore com o seu romance homônimo desnecessário, cujo "[... protagonista [do romance] nem sequer sabe que a escolha de
28. ZAMBRA, 2014, p. 70-71

29. ZAMBRA, 2014, p. 82

30. ZAMBRA, 2014, p. 81

31. ZAMBRA, 2014, p. 81 
32. ZAMBRA, 2014, p. 81 33.ZAMBRA, 2014, p. 70

34. Claus Clünver traz em seu artigo Inter textus / inter artes / inter media questões sobre as complicações do uso do termo Interarte em outros por razões de intraduzibilidade para línguas como o alemão (este causa dificuldades consideráveis num discurso internacional) [...]", mas também pela " [...] insuficiência da designação usada até agora $[\ldots]^{\prime \prime}$ que podemos associar a noçăo de estudos entre artes a intermídia, que "[...] diz respeito não só àquilo que nós designamos ainda amplamente como 'artes' (Música, Literatura, Plásticas, Arquitetura bem crmo formas mistas, como Ópera Teatro Cinema), mas também às 'mídias' seus textos, já costumeiramente assim designadas na maioria das línguas e culturas ocidentais." Cf.: CLUNVER, 2016, p 18. Deste modo, podemos entender intermidia no sentido estrito de combinação de mídias (Medienkombination), que incluî fenômenos como ópera, filme, teatro, instacõos cominados/luminuras, Sound Art, história em quadrinhos ou, noutra terminologia, as chamadas formas multimídia, de mescla de mílias e intermidiáticas. Cf.: RAJEWSKY, 2012, p. 58.

35. ZAMBRA, 2014, p. 81

36. ZAMBRA, 2014, p. 81 um vaso é, por si só, uma forma de arte, que um bonsai não é uma árvore bonsai porque a palavra já contém o elemento vivo." 32 Descobre-se nesta passagem que a personagem de Bonsai escreve um livro, ta mbém chamado "Bonsai", no qual as personagens se assemelham com a história do autor-empírico Alejandro Zambra. É assim outro modo em que se constrói o efeito metaliterário da narrativa. O leitor empírico se depara com o romance que Júlio escreve, assimilando as duas histórias como uma mesma história.

Ele nunca se esqueceu dela, diz Júlio, Fez a sua vida, teve filhos e tudo mais, se separou, mas nunca se esqueceu dela. Ela era tradutora, como você, mas de japonês. Eles se conheceram quando estudavam japonês, muitos anos antes. Quando ela morre, ele pensa que a melhor maneira de a recordar é fazer novamente um bonsai. ${ }^{33}$

A comparação de Júlio não só estabelece o efeito metaliterário, como também trava uma relação interartes ${ }^{34}$, entre a arte de cuidar de um bonsai e a arte de escrever um romance. Assim, Júlio diz que "[...] cuidar de um bonsai é como escrever [...]" ${ }^{35} \mathrm{e}$ que "[...] escrever é como cuidar de um bonsai" ${ }^{36}$, onde a mbas as artes, a de cuidar de um bonsai e a de escrever um livro, são necessários dois recipientes: o jardineiro e o vaso, o escritor e a folha. Essas artes demandam a necessidade de que alguém possa esculpir a obra. Na epígrafe do romance, Gonzalo Millán diz que "[...] a dor se talha e se detalha [...]" ${ }^{37}$, invocando, para ambas artes, a dor como um limite, um controle, seja para estruturação de um romance ou para cuidar de uma árvore em miniatura

Uma natureza contida em um marco, um sentimento talhado por meio da escrita: construir um bonsai é artificializar a natureza, escrever um livro é detalhar e controlar os sentimentos de maneira que se faça possível uma obra de arte; somente ao custo da mutilação que é possível criar um bonsai e escrever um livro. A possibilidade da arte se baseia na ascese. ${ }^{38}$

Assim, concluímos que a mbas as artes se interligam na ideia de que, para a sua construção, é preciso podar, talhar a sua natureza.

\section{Pensar a imagem do bonsai}

O desejo do homem de controlar da natureza é recorrente. A exemplo disto estão as barragens para mineração, barragens para ondas em praias, transposição de percursos de rios a fim de atender uma demanda de produção agrícola, tal qual a estufa, que também atende esta função sob um controle ainda mais árduo feito pelo homem, "[...] no qual o clima interno [da estufa] - luz, temperatura, umidade - é controlado para que se atinja o rendimento máximo de seus produtos." ${ }^{39} \mathrm{~A}$ criação de jardins também adentra nesta artificialidade
37. ZAMBRA, 2014, p. 7. [epígrafe]

38. No original: "Una naturaleza contenida en un marco, un sentimiento tallado a traves de artificializar la naturaleza, escribir un libro es detallar y controlar lo sentimientos de manera que hagan posible una obra de arte; solo a costo de la mutilación es posible crear un bonsái y escribir un libro. La posibilidad del arte se basa en ascesis." Cf.: ARECO, 2016, p. 10. (tradução nossa)

39. HYUSSEN, 2014, p.83 
40. ZAMBRA, 2014, p. 81

41. CUAQUELIN, 2007, p. 63 e domesticação da natureza, cuja sua forma submetida à intervenção humana é que nos interessa aqui.

O bonsai, cujo nome, por si só, "[...] já inclui o elemento vivo [..." "40 é também uma dessas formas domesticadas da natureza, submetidas à intervenção humana. Diferentemente daquelas pinturas que Cauquelin nos propõe, o bonsai é, em sua composição, o elemento vivo da natureza, trazendo forma viva a um ambiente interno, a um espaço urbano. $\mathrm{O}$ bonsai é uma espécie de jardim, que "[...] oferece [...] esse paradoxo amável de ser 'um fora dentro' [...]” ${ }^{41}$, mas que não se reduz somente a isso, ele é, ta mbém, uma aproximação às ideias de estufa propostas pelo ensaísta Andreas Huyssen.

Para Huyssen, o jardim e a estufa se distinguem em conceito, uma vez que, para ele,

[...] o jardim evoca as origens bíblicas, o lento crescimento orgânico, a serenidade mental e a natureza romântica. Mas estufa não é jardim. Diversa mente do jardim, ela é a natureza semeada e cultivada numa estrutura arquitetônica feita de vidro e aço, que protege o crescimento das plantas do tempo inclemente e das mudanças sazonais. ${ }^{42}$

Diante desta distinção, como pensar o bonsai dentro do romance? A árvore de Júlio, cuja narrativa lhe atribui ressignificações, está entre o intermédio desses dois conceitos.
Isto é, o bonsai precisa de um recipiente - uma arquitetura - para tornar-se bonsai, pois "[...] uma vez fora do vaso, a árvore deixa de ser um bonsai [...]"43, à semelhança da estufa, que é constituída, em seu conceito, por um espaço artificial, "[...] abole e reescreve as fronteiras entre natureza e cultura." ${ }^{44}$ Logo, o bonsai de Júlio, "[...] que segue o curso indicado pelos arames [...]"45 é uma natureza domesticada "[...] sendo submetida a intervenções humanas, como excertos e cruza mentos, num meio hipernatural." ${ }^{46}$

Tal como a estufa, o jardim, como nos lembra Huyssen, é "[...] ta mbém um espaço artificialmente criado [...]" ${ }^{47}$ e que, como propõe Cauquelin, se ele se "[...] separa da cidade, ele também se separa de natureza furiosa, tempestuosa ou desértica." ${ }^{48} \mathrm{O}$ bonsai é a domesticação da grandiosidade da natureza, da árvore, cuja forma natural solicita um espaço para seus desdobramentos e ramificações. A miniatura da grandiosidade estabelece uma correlação entre a estufa, que solicita uma estrutura arquitetônica, com o jardim, que requer um crescimento orgânico. O bonsai, uma árvore para cultivo dentro de casa, evoca, dentro da narrativa, uma figuração para sua função romântica e orgânica do jardim, tanto quanto a sua função modernizada e estruturada do crescimento da árvore, como uma estufa. Zambra discorre em seu romance:
43. ZAMBRA, 2014, p. 81.

44. HUYSSEN, 2014, p. 86

45. ZAMBRA, 2014, p. 86

46. ZAMBRA, 2014, p. 86.

47. HUYSSEN, 2014, p. 86

48. CAUQUELIN, 2007, p. 63 
Há meses espera o momento em que o bonsai irá se enca minhar para sua forma perfeita, a forma serena e nobre que previu A árvore segue o curso indicado pelos arames. Dentro de poucos anos, pretende Júlio, ela vai finalmente ficar idêntica ao desenho. ${ }^{49}$

Então é o bonsai um jardim-estufa? A certo modo, quando pensado sob a ótica do romance, sim. Em Bonsai (2014), ao mesmo tempo que Júlio espera que a árvore cresça em sua forma orgânica, os arames entrelaçados projetam uma forma planejada, vez e outra a árvore também aparece como uma figura romantizada pelo narrador, dando a entender que motivação de Júlio para fazer um bonsai é Emília. "Ele nunca se esqueceu dela, diz Júlio. [...] Quando ela morre, ele pensa que a melhor maneira de recordá-la é fazer novamente um bonsai. [...] Não, desta vez ele não compra, ele mesmo o faz. Consegue manuais, consulta especialistas, planta as sementes, fica meio louco." 50

O narrador, que, de forma despretensiosa, conta a história de uma relação falida, além do trágico pela morte de Emília, mostra como o bonsai surge para metaforizar a urbanização e modernização do homem, que abandona a natureza original, aquela que Huyssen vai intitular de primeira natureza ${ }^{51}$, para mostrar-se numa segunda natureza, aquela produzida pelo humano, civilizatória, industrial e moderna. O suicídio de
Emília e o bonsai de Júlio são formas exempla res do controle do homem sobre a sua própria natureza e de seu aprisionamento ao universo urbano modernista.

O bonsai é a representação do relacionamento do Júlio e Emília, símbolo criado em diversas instâncias dentro da narrativa. Bonsai (2014), assim como o jardim e a estufa, é a "[...] representação dos paraísos artificiais da cultural do início do século XXI, obcecado pela memória." ${ }^{2}$ A decisão de Júlio de construir duplamente um bonsai (o romance e a árvore) é referência, em diferentes recortes, à sua relação com Emília alcançando um lugar melancólico "[...] de algo muito distante ou que ficou no passado." ${ }^{53}$

\section{Edição como recipiente}

E por último, destacamos à composição ${ }^{54}$ que o livro recebe pela editora brasileira Cosac Naify, que se destaca(va) por suas inovadoras edições. Pensando numa questão estético-visual e o material narra tivo do livro, é possível estabelecer um diálogo entre as formas e as características atribuídas ao produto físico junto ao seu título e conteúdo. Gruszynki e Fialho afirmam que o "[... projeto gráfico conjuga de forma criativa e inovadora a linguagem visual e material do livro com o conteúdo do texto." ${ }^{55} \mathrm{O}$ design do livro recebe uma diagramação mais podada, isto é, a mancha do livro - o texto - é centralizada, ocupando somente o miolo do livro, como estivessem semeada dentro de um vaso.
52. HUSSEN, 2014, p. 90

\section{HUSSEN 2014, p. 91}

54. Segundo, Gérard Genette, a composição é [...] a escolha dos caracter e de sua diagramação, é o que dá forma de livro a um exto." Cf.: GENETTE, 2009, p. 35

55. GRUSZNSKI, Ana; FIALHO, Luise Cristine Spieweck. Cosac Naify: uma editora, um editor, uma ousada proposta gráfica editorial. Disponível em: http://portalintercom.org.br/ anais/nacional2017/resumos/ R12-1252-1.pdf. Acesso em 17 jun. 2019. 
$\mathrm{Na}$ capa e na contracapa, somos apresentados a um pontilhado indicando uma possibilidade de poda, de recorte, que se associa à produção de livro em miniatura, de um livrobonsai, tal qual a arte do cultivo da árvore em miniatura Integra-se a essa composição a questão do designer (o homem, profissional) sob o controle da produção do livro, tal qual é a manifestação do controle do homem no cuidado de um bonsai. Em a mbas produções, a ideia é a mesma: manter a harmonia e o controle da arte e da natureza, sob a ótica do homem, que anseia o controle sob todas as coisas.

Diante da questão editorial, observemos que a existência física do romance Bonsai de Zambra exerce uma função harmoniosa de conjugação editorial entre os elementos extratextuais (recipiente) e textuais (a narrativa - árvore). O tamanho da obra é relevante também para a aproximação entre a arte de cultivar um bonsai e produzir o romance. Com suas 91 páginas na edição brasileira, próxima à edição original, que tem 90 páginas, o texto está disposto sobre o seu recipiente e condiz com a condição de um bonsai, em que a escolha do recipiente foi trabalhada.
Figura 1 - Capa e contracapa de Bonsai, com destaque às indicações de picote

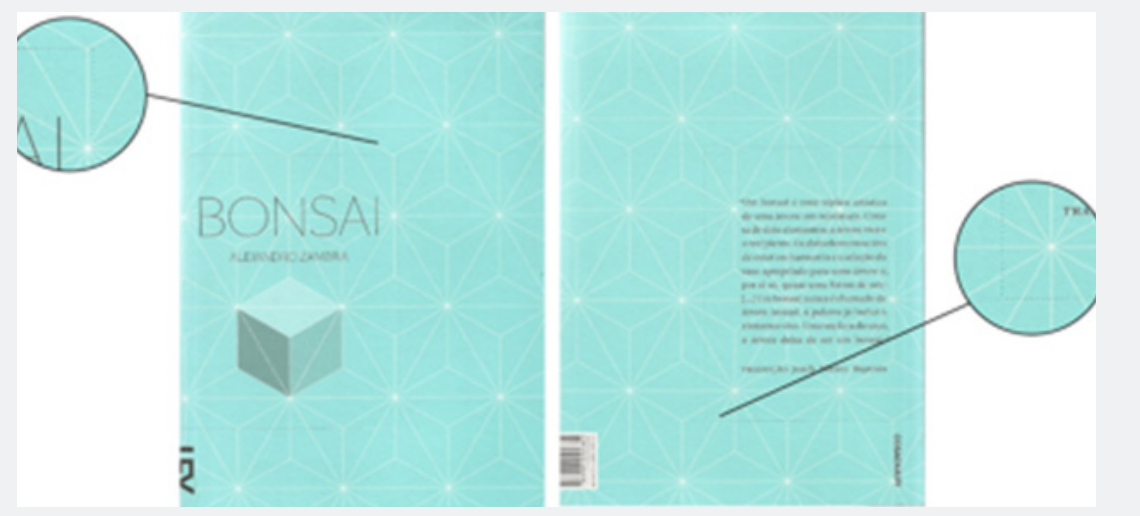

Fonte: Disponível em: http://portalintercom.org.br/anais/nacional2017/resumos/ R12-1252-1.pdf. Acesso em: 17 jun. 2019

Figura 2 e 3 - Páginas miolo de Bonsa
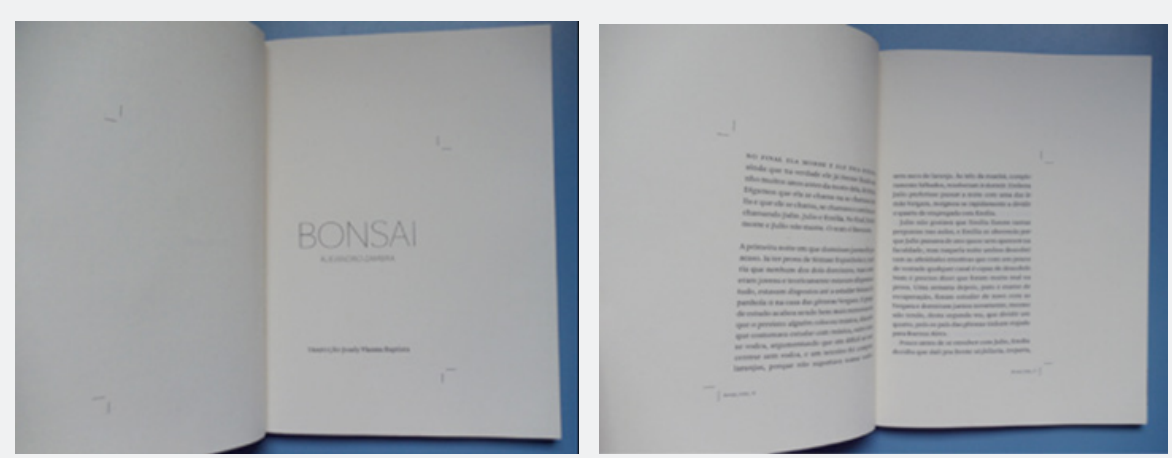

Fonte: Disponível em: http://portalintercom.org.br/anais/nacional2017/resumos/ R12-1252-1.pdf. Acesso em: 17 jun. 2019 
56. No original: “[...] historia larga de un libro corto." Cf.

ZAMBRA, 2018, p. 285.

57. No original: “[...] libro que, del mismo modo que un bonsái no es un árbol, más que una novela corta o un relato largo es una novela-resumen o, justamente, una novelabonsái." Cf.: ANAGRAMA. Bonsái. Disponível em: https://www.anagrama-ed.es/ libro/narrativas-hispanicas/ bonsai/9788433932471/ EB_30. Acesso em: 17 jun. 2019

58. HUYSSEN, 2014, p. 90.

\section{Os bonsais de Zambra}

Como vimos, a feitura de um bonsai é considerada uma arte, além de sua produção ser uma demonstração dos anseios de homem sobre a domesticação e controle da grandiosidade da natureza. A literatura, assim como o bonsai, é uma arte, que no romance de Alejandro Zambra, compreendemos ser possíve domesticar e que, assim como o processo de crescimento de um árvore a história de Bonsai é "[...] uma história longa de um livro curto." ${ }^{16}$ Em Bonsai (2014), o que vemos é a grandiosidade de uma arte em formato de miniatura, e o livro "[...] do mesmo modo que um bonsai não é uma árvore, mais que um romance curto ou um relato longo é uma novela-resumo, uma novela bonsai." ${ }^{27}$

A novela-resumo de Alejandro Zambra nos permite pensar como a metalitera tura e o hipertexto fomentam a criação de um novo produtor, que, ademais de fazer referências exteriores ( $E m$ busca do tempo perdido e Tantalia), ta mbém traz uma autorreflexão da própria narrativa de Zambra. Ademais, a tessitura entre as interartes (editorial, literária e feitura de um bonsai) demonstra um exercício extra autor, da qual percebemos, assim como a estufa, uma combinação de "[...] duas tradições: a do jardim e a da arquitetura. ${ }^{58} \mathrm{~A}$ arquitetura da edição brasileira coloca em xeque a questão estrutural e física do romance, combinando-a com forma e o conteúdo.
Torna-se repetitivo, porém necessário, dizer que o Bonsai (2014) imita a arte de criar árvores em vasos, e que para além disso, é capaz de ressignificar outras literaturas junto às correntes contemporâneas.

\section{REFERÊNCIAS}

ANAGRAMA. Bonsái. Disponível em: https://www.anagrama-ed.es/ libro/narrativas-hispanicas/bonsai/9788433932471/EB_30. Acesso em: 17 jun. 2019

ANAGRAMA. Catálogo - Bonsái. Disponível em: https://www. anagrama-ed.es/libro/narrativas-hispanicas/bonsai/9788433932471/ EB 30. Acesso em: 7 out. 2018.

ARECO, Macarena. Imaginarios de espacio y sujeto: Japonerías en la narrativa Argentina, Chilena y Mexicana reciente. Nueva Revista de Pacífico, Valparaíso , n. 65, p. 4-17, 2016

CAUOUELIN, Anne. A invenção da paisagem. Tradução de Marcos Marcionilo. São Paulo: Martins, 2017. (Coleção Todas as Artes)

CLÜNVER, Claus. Inter textus / inter artes / inter media. Aletria: Revista de Estudos Literários, v. 14, p. 10-41, dez. 2006. ISSN $2317-$ 2096. Disponível em: http://www.periodicos.letras.ufmg.br/index.php/ 
aletria/article/view/1357. Acesso em: 21 ago. 2020. doi: http://dx.doi. org/10.17851/2317-2096.14.2.10-41.

GÉRARD, Genette. Palimpsestos: a literatura de segunda mão, Tradução de Luciene Guimarães et al. Belo Horizonte. FALE/UFMG, 2010. [Edição restrita aos estudantes da FALE/UFMG]

GÉRARD, Genette. Paratextos editoriais. Tradução de Álvaro Faleiros. São Paulo: Ateliê Editorial, 2009.

GRUSZNNSKI, Ana; FIALHO, Luise Cristine Spieweck. Cosac Naify: uma editora, um editor, uma ousada proposta gráfica e editorial. Disponível em: http://portalintercom.org.br/anais/nacional2017/resumos/R12 1252-1.pdf. Acesso em: 17 jun. 2019.

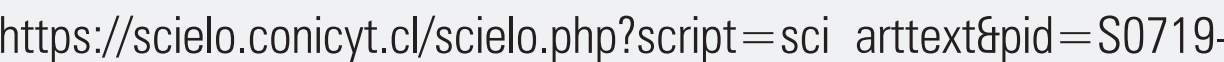
$51762016000200001 \mathrm{glng}=$ ptEnrm=iso. Acesso em: 21 ago. 2020 http://dx.doi.org/10.4067/S0719-51762016000200001.

HUYSSEN, Andreas. Culturas do passado-presente: modernismos, artes visuais, políticas da memória. Tradução de Vera Ribeiro. Rio de Janeiro: Contraponto, 2014

RAJEWSKY, Irina. A fronteira em discussão: 0 status problemático das fronteiras midiáticas no debate contemporâneo sobre intermidialidade. In: DINIZ, Thais Flores Nogueiras; VIEIRA, Andres Soares. (Orgs.). Intermidialidade e estudos interartes: desafios da arte contemporânea. Belo Horizonte: Rona Editora, FALE/UFMG, 2012. p. 51-74.

SANTOS, Daniel. A crise da ficção na história literária latino-americana: o caso Alejandro Zambra. X Seminário Internacional de História da Literatura, 2013, Porto Alegre. Anais. Disponível em: www.ebooks. pucrs.br/edipucrs/Ebooks/Web/xsihl/media/comunicacao-17.pdf. Acesso em: 15 jun. 2019.

VOLPATO, Cadão. Zambra, um escritor com espírito de botânico. Valor Econômico, 4 abr. 2013. Disponível em: https://www.valor.com. br/cultura/3072360/zambra-um-escritor-com-espirito-de-botanico. Acesso em: 17 jun. 2019

WILLEM, B. El espacio narrativo en la novela chilena postdictatorial: casas habitadas. Boston (USA): Leiden, 2016. www.ebooks.pucrs.br/ edipucrs/Ebooks/Web/xsihl/media/comunicacao-17.pdf. Acesso em: 15 jun. 2019

ZAMBRA, Alejandro. Bonsái. Madrid. Editorial Anagrama, 2015.

ZAMBRA, Alejandro. Bonsai. São Paulo. Cosac Naify, 2014.

ZAMBRA, Alejandro. No leer. Madrid. Editorial Anagrama, 2018.

Recebido em: 05/02/2020

Aceito em: 25/08/2020 